\title{
TENDÊNCIAS DE PESQUISA EM INFORMAÇÃO E TECNOLOGIA: ANÁLISE DO GT 8 NO ENCONTRO NACIONAL DE PESQUISA E PÓS-GRADUAÇÃO EM CIÊNCIA DA INFORMAÇÃO
}

\author{
Orientando: Tatiane Nunes Xavier \\ Graduada em Biblioteconomia \\ Orientador: Prof. Dr. Henry Poncio Cruz de Oliveira \\ Doutor em Ciência da Informação \\ Professor do DCI/PPGCI/UFPB
}

\section{Resumo}

No decorrer dos anos, o avanço tecnológico e o uso intenso da informação e das tecnologias tem impactado nas atividades de produção científica. O objetivo deste trabalho é analisar a evolução das principais temáticas discutidas no GT 8 da ANCIB, no período de 2008 a 2015, e traçar tendências de pesquisa no GT. O estudo surge pela necessidade de saber como evoluem as temáticas de pesquisa discutidas no GT8, desde sua criação até os dias atuais. Os procedimentos metodológicos adotados foram caracterizados por um estudo descritivo e exploratório com abordagem quantitativa, constituindo-se por meio de um levantamento detalhado dos anais do ENANCIB. A partir das análises que foram realizadas, verificamos, pelas temáticas abordadas, tendências no âmbito da pesquisa em Ciência da Informação nas comunicações da ANCIB, no interior do GT8 do ENANCIB. Foram adotadas entre as técnicas de apresentação, as nuvens de tags para visualização dos resultados. Os resultados indicam que durante todo o percurso do GT, houve produção da temática destacada, indicando que ela deve permanecer ativa. Entre as temáticas de pesquisa, a categoria Arquitetura da Informação teve destaque abrigando o maior número de ocorrências publicados no GT 8 durante o período em estudo, entendemos que assim, se configura como tendência de pesquisa.

Palavras-chave: Informação e Tecnologia. Produção científica. Ciência da Informação. 